\title{
FACTORS CONTRIBUTING TO POST-OPERATIVE HYPOCALCAEMIA AFTER TOTAL THYROIDECTOMY- EXPERIENCE IN A TERTIARY CARE GOVT. HOSPITAL IN EASTERN INDIA
}

\author{
Bijan Basak1, Kaustuv Das Biswas², Ankit Choudhary33, Sourav Roy4, Swapan Kumar Ghosh ${ }^{5}$ \\ ${ }_{1}^{1}$ Associate Professor, Department of ENT, Head and Neck Surgery, IPGMER \& SSKM Hospital, Kolkata, West Bengal, India. \\ ${ }^{2}$ RMO-Cum-Clinical Tutor, Department of ENT, Head and Neck Surgery, IPGMER \& SSKM Hospital, Kolkata, West Bengal, India. \\ 3 Senior Resident, Department of ENT, Head and Neck Surgery, IPGMER \& SSKM Hospital, Kolkata, West Bengal, India. \\ ${ }^{4}$ Senior Resident, Department of ENT, Head and Neck Surgery, IPGMER \& SSKM Hospital, Kolkata, West Bengal, India. \\ 5Professor, Department of ENT, Head and Neck Surgery, IPGMER \& SSKM Hospital, Kolkata, West Bengal, India.
}

\section{ABSTRACT}

\section{BACKGROUND}

Postoperative hypocalcaemia is a common complication after total thyroidectomy but most often it is transient. Although these are mostly amenable to calcium and vitamin D supplementation, symptomatic patients sometimes need prolonged hospitalization following thyroid surgery, leading to increased healthcare costs. In the present study, we tried to find out factors which can predict the occurrence of post-operative hypocalcaemia \& hypoparathyroidism in total thyroidectomy patients, facilitating their early detection and institution of definitive management in time, preventing emergency admissions \& catastrophes.

\section{METHODS}

A prospective observational study was carried out in the Department of ENT \& Head- Neck Surgery of a tertiary care govt. hospital in eastern India. Patients who underwent total thyroidectomy for multinodular goitre (MNG) and adenomatoid goitre (AG) or total/completion thyroidectomy for well differentiated thyroid carcinomas (WDTC), in the age group of 20-55 years were included in our study. We recorded the following parameters: Age, gender distribution of cases, type of operation, pre-operative Fine Needle Aspiration Cytology (FNAC) status, size of thyroid nodule operated (based on pre-operative ultrasonographic study), number of parathyroid glands preserved during operation, pre-operative vitamin D levels, post-operative serum calcium levels at 6 hours \& 12 hours (positive i.e. increasing slope \& non-positive i.e. decreasing/non-changing slope), early post-operative serum iPTH levels (at 6 hours), development of symptomatic hypocalcaemia- transient or permanent.

\section{RESULTS}

In the present study we measured serum calcium level 6 hours $\& 12$ hours post-operatively. It has been found that patients with serum calcium levels on positive slope have lesser chances of occurrence of symptomatic hypocalcaemia \& permanent hypocalcaemia than those on non-positive slope. We found that patients having serum iPTH level between $15-65 \mathrm{pg} / \mathrm{ml}$ showed lesser propensity to develop hypocalcaemia in comparison with those with serum iPTH level $<15 \mathrm{pg} / \mathrm{ml}$. In our study, it has been found that all the 3 cases who developed permanent hypocalcaemia were suffering from vitamin D deficiency; whereas, patients with normal vitamin D levels posed lesser risk of developing significant hypocalcaemia. In our observation, patients with only two parathyroid glands identified per-operatively have more chances of developing hypocalcaemia \& those in whom all four parathyroid glands were preserved, very low risk of hypocalcaemia is associated. Furthermore, preservation of functional parathyroid gland with intact blood supply is found to be of immense importance than mere identification of the glands. In our series, it has been noted that with increase in the size of thyroid nodule, chances of hypocalcaemia increases. Patients undergoing complete thyroidectomy for histopathological report of WDTC in a previously benign (based on pre-operative FNAC) thyroid nodule, increased chances of development of post-operative hypocalcaemia.

\section{CONCLUSIONS}

Development of hypocalcaemia post thyroidectomy is multifactorial, some of which are predictable \& some of which are correctable, either pre or post operatively, in order to reduce the chances of development of hypocalcaemia. Assessment of these factors helps in early identification of patients who are prone to develop significant hypocalcaemia in combination with the peroperative factors \& ultimately helps in early institution of definitive replacement therapy, preventing unnecessary emergency readmission $\&$ helps in reducing the duration of hospital stay by facilitating early discharge, thus overall reducing burden on the healthcare system.

\section{KEY WORDS}

Hypocalcaemia, Hypoparathyroidism, Thyroidectomy, iPTH, Risk Factor

HOW TO CITE THIS ARTICLE: Basak B, Biswas KD, Choudhary A, et al. Factors contributing to post-operative hypocalcaemia after total thyroidectomy- experience in a tertiary care govt. hospital in Eastern India. J. Evolution Med. Dent. Sci. 2019;8(26):20902096, DOI: $10.14260 /$ jemds/2019/460

'Financial or Other Competing Interest': None.

Submission 27-04-2019, Peer Review 17-06-2019,

Acceptance 24-06-2019, Published 01-07-2019.

Corresponding Author:

Dr. Kaustuv Das Biswas,

Avishikta-1, Flat-2B-402,

369/1, Purbachal Kalitala Road,

P. O. Haltu, Kolkata-700078,

West Bengal, India.

E-mail:dr.kaustuv.82@gmail.com

DOI: $10.14260 /$ jemds $/ 2019 / 460$

\section{BACKGROUND}

Postoperative hypocalcaemia is a common complication after total thyroidectomy but most often it is transient.1,2,3,4 Hypoparathyroidism leading to decreased serum calcium, clinically may present with muscle cramps, perioral and peripheral paraesthesia, carpopedal spasm or tetany, and/or confusion. Although these are mostly amenable to calcium and vitamin D supplementation, symptomatic patients sometimes need prolonged hospitalization following thyroid surgery, leading to increased healthcare $\operatorname{costs.}^{5}$ As per 
literature search, incidence of hypocalcaemia varies widely $(0.3 \%$ to $66.2 \%) .5,6$

Depending on the extent of parathyroid gland damage, hypocalcaemia may be transient, resolving within a few months, or permanent, lasting for longer than 1 year, sometimes requiring lifelong oral calcium and vitamin $\mathrm{D}$ supplementation. ${ }^{7}$ Incidence ranging from $10 \%$ to $50 \%$ for transient hypocalcaemia and $0 \%-2 \%$ for permanent hypocalcaemia have been reported.1,2,8,9 Unlike other common complications like recurrent laryngeal nerve palsy or neck haematoma, which mostly develop with first 24 hours post-operatively, hypocalcaemia usually presents 24-48 h postoperatively; ensuing diagnostic dilemma and prolonging hospital stay, needing close observation \& multiple laboratory investigations. $8,10,11$ Although recently prolonged patient stay at hospital is avoided 12,13 and patients are preferably discharged within 24 hours post-op, it is very essential to identify patients at high risk of developing symptomatic hypocalcaemia so as to initiate preventive treatment early in order to reduce their chances of emergency ward visit after total thyroidectomy.12-14 Permanent hypocalcaemia is due to persistent postoperative hypoparathyroidism because of devascularisation, injury or inadvertent dissection of parathyroid glands during the surgery.7,15 It is to be noted that post-operative hypocalcaemia can be related to multiple factors, including surgical technique, the definition of hypocalcaemia, criteria of the series reported and use of prophylactic calcium supplementation in the perioperative period. ${ }^{15,16}$

In the present study we tried to find out factors which can predict the occurrence of post-operative hypocalcaemia \& hypoparathyroidism in total thyroidectomy patients, facilitating their early detection and institution of definitive management in time, preventing emergency admissions \& catastrophes.

\section{METHODS}

\section{Study Design}

Prospective observational study.

\section{Place of Study}

Department of ENT \& Head- neck Surgery of a tertiary care govt. hospital in eastern India.

\section{IEC Clearance}

Prior to commencement of the study institutional ethical committee clearance was sought for \& was obtained.

\section{Inclusion Criteria}

Patients who underwent total thyroidectomy during the period February 2017 to September 2018 either for benign diseases like multinodular goitre (MNG) and adenomatoid goitre(AG) or total/completion thyroidectomy for well differentiated thyroid carcinomas (WDTC) in early stage (Stage I i.e. $<\mathrm{T} 2 / \mathrm{N} 0 / \mathrm{M} 0$ ) and in the age group of 20-55 years were included in our study. Pre-operative serum calcium, Vitamin D (25- hydroxy Vitamin D3) level \& intact parathyroid hormone level (iPTH) were obtained in all the cases in addition to general anaesthesia fitness \& establishment of euthyroid status.

\section{Exclusion Criteria}

Patients with hypocalcaemia, abnormal parathyroid hormonal levels \& with any history of surgery in neck (Other than hemithyroidectomy for thyroid disorders) were excluded from the study.

\section{Sample Size}

Thus 42 patients who were operated in our department during the above-mentioned period \& fulfilling the inclusion $\&$ exclusion criteria were included in the study.

\section{Sampling Technique}

No further sampling technique was applied as all the 42 cases as per inclusion \& exclusion criteria were selected for the study.

\section{Consent Process}

The patients included in the study were operated as part of their definitive management plan \& as they consented for the operation, the post-operative vital parameters were recorded for observational study. As there was no definite intervention or withholding treatment was involved in the study process, separate consent was not sought for. Personal information of the patients was kept confidential in the course of the study.

The patients were operated by the same surgical team well trained in thyroid surgery. In all of the patients, meticulous thyroid gland dissection was performed removing all thyroid tissue including posterior thyroid capsule \& pyramidal lobe, as per the anatomical configuration with identification of recurrent laryngeal nerves bilaterally. Parathyroid glands were identified bilaterally \& preserved with an intact vascular pedicle. During the surgical procedure, inferior thyroid artery was identified \& its branch supplying the parathyroid gland was preserved followed by ligation of another branch (es) of inferior thyroid artery. Parathyroid gland auto- transplantation was not performed in any of the patients in our study \& in none of the specimens submitted for histopathological examination, inadvertently removed parathyroid gland was found.

Post-operatively total thyroidectomy patients were put on thyroxine. Serum calcium levels were monitored postoperatively at 6 hours $\& 12$ hours \& then as per symptoms or based on clinical findings. Serum iPTH level was obtained 6 hours post-operatively. Oral calcium supplementation (500 mg twice daily) along-with single dose of Vitamin D3 orally on the $1^{\text {st }}$ post-operative day was reserved for patients developing serum calcium levels $<7.5 \mathrm{mg} \%$ or patients who were on non-positive slope on 6 hours \& 12 hours postoperative serum calcium estimation. The dose was titrated as per clinical improvement in symptoms of hypocalcaemia developed in the patients. In few cases intravenous calcium supplementation was required to combat the acute transient hypocalcaemia. The dose is gradually tapered off or continued in the long term follow up period of 6 months to 1 year as per response to treatment.

\section{Rationale for Sample Size}

We followed the inclusion \& exclusion criteria stringently while selecting patients to be included in study population \& each case was followed up for a period of minimum 6 months 
to maximum 12 months, the above-mentioned sample size was available for the study at our institution.

As per the pre-operative FNAC status the cases can be distributed as follows-

\begin{tabular}{|c|c|}
\hline Pre-Operative FNAC Status & No. of Cases (\%) \\
\hline MNG & $7(16.7 \%)$ \\
\hline AG & $9(21.4 \%)$ \\
\hline WDTC- Papillary carcinoma & $18(42.9 \%)$ \\
\hline WDTC- Follicular neoplasm & $8(19.0 \%)$ \\
\hline Total & $\mathbf{4 2}(100 \%)$ \\
\hline Table 1. Showing Distribution of Cases Depending Upon \\
Pre-Operative FNAC Status \\
\hline
\end{tabular}

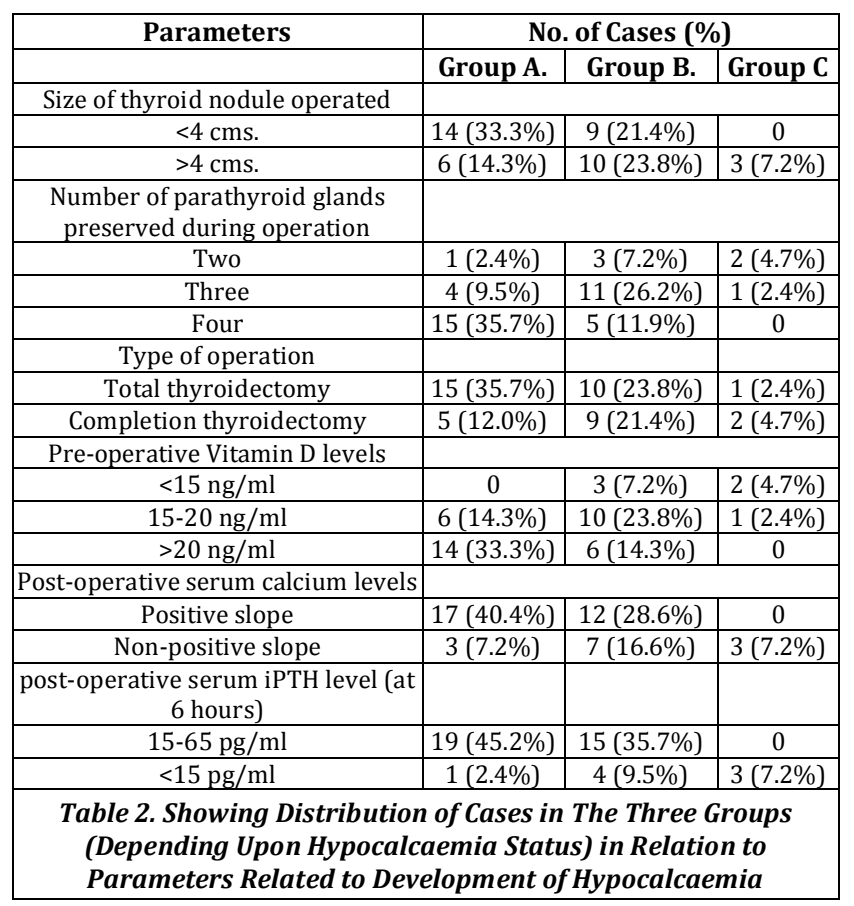

We recorded the following parameters-

1. Age.

2. Gender distribution of the cases.

3. Type of operation.

4. Pre-operative Fine Needle Aspiration Cytology (FNAC) status.

5. Size of thyroid nodule operated (Based on pre-operative ultrasonographic study).

6. Number of parathyroid glands preserved during operation.

7. Pre-operative Vitamin D levels.

8. Post-operative serum calcium levels at 6 hours \& 12 hours (Positive i.e. increasing slope \& non-positive i.e. decreasing/non-changing slope).

9. Early post-operative serum iPTH levels (At 6 hours).

10. Development of symptomatic hypocalcaemia- transient or permanent.

\section{RESULTS}

In the present study mean age of the patients was found to be 35.8 years. There was a female preponderance ( 36 cases i.e. $85.7 \%$ were female as compared to 6 cases i.e. $14.3 \%$ ). In 16 cases (i.e. $38.1 \%$ ) the primary operation was hemithyroidectomy for benign thyroid disease (MNG/AG) with histopathological study coming out as WDTC, for which completion thyroidectomy was performed. Rest of the 26 cases (i.e. 61.9\%) underwent total thyroidectomy either for WDTC or MNG/AG involving both lobes of thyroid gland.

In the present study, 3 patients (i.e. $7.2 \%$ ) developed permanent hypocalcaemia- classified as Group C. 19 patients (i.e. 45.2\%) developed transient hypocalcaemia- classified as Group B. In rest of the 20 patients (i.e. $47.6 \%$ ) no symptoms of hypocalcaemia developed- classified as Group A.

In the following table we summarise our findings of the parameters closely related to development of hypocalcaemia in the above mentioned three groups.

From the above depicted data, we have found that all the cases of permanent hypocalcaemia developed in patients with thyroid nodule $>4 \mathrm{~cm}$ in size whereas in cases with nodule size $<4 \mathrm{~cm}$ in size, 9 cases (21.4\%) developed transient hypocalcaemia \& 14 cases (33.3\%) developed no symptoms of hypocalcaemia.

It has been noted that when all four parathyroid glands were preserved per-operatively, only 5 patients $(11.9 \%)$ developed transient hypocalcaemia, no patients developed permanent hypocalcaemia and 15 patients (35.7\%) did not develop any symptoms of hypocalcaemia. On the other hand, when only two of the four parathyroid glands were preserved per-operatively, 2 patients $(4.7 \%)$ developed permanent hypocalcaemia, 3 patients (7.2\%) developed transient hypocalcaemia and 1 patient $(2.4 \%)$ developed no symptoms of hypocalcaemia. It was also found worth mentioning that in 1 case $(2.4 \%)$ although three of the four parathyroid glands were identified per-operatively, but unfortunately those glands turned out to be non-functional, leading to development of permanent hypocalcaemia.

While considering the type of surgery performed in the patients, it came out as only 1 patient $(2.4 \%)$ developed permanent hypocalcaemia, 10 cases $(23.8 \%)$ transient hypocalcaemia \& 15 cases (35.7\%) developed no symptoms of hypocalcaemia at all in the primary total thyroidectomy group whereas permanent hypocalcaemia occurred in 2 cases $(4.7 \%)$, temporary hypocalcaemia in 9 cases $(21.4 \%)$ \& no hypocalcaemia in 5 cases $(12 \%)$ only in the completion thyroidectomy group.

While recording the pre-operative Vitamin D levels of the patients, we found that of the 3 cases who developed permanent hypocalcaemia, 2 had Vitamin D levels $<15 \mathrm{ng} / \mathrm{ml}$ (i.e. severe deficiency) \& 1 had Vitamin D level between 15$20 \mathrm{ng} / \mathrm{ml}$ (i.e. borderline deficiency). On the contrary among the patients with Vitamin D levels $>20 \mathrm{ng} / \mathrm{ml}, 14$ patients (33.3\%) developed no hypocalcaemia, 6 patients $(14.3 \%)$ developed transient hypocalcaemia and none developed permanent hypocalcaemia.

We monitored serum calcium levels twice (i.e. 6 hours \& 12 hours post-operatively) in order to get a trend of serum calcium level of the patients. It has been noted that among patients who are on positive slope having gradually increasing serum calcium levels, only 12 cases (28.6\%) developed transient hypocalcaemia, 17 cases (40.5\%) developed no symptoms of hypocalcaemia \& none developed permanent hypocalcaemia. On the other hand, patients on non-positive slope with gradually decreasing or nonchanging serum calcium levels, were followed up more closely with serum calcium estimation repeated every 24-48 hourly. Ultimately 3 of them (7.2\%) landed up into permanent hypocalcaemia, 7 cases (16.6\%) developed 
transient hypocalcaemia recovering later \& 3 cases $(7.2 \%)$ did not developed any symptoms of hypocalcaemia.

Parallel monitoring of serum iPTH was also done 6 hours post-operatively which emanated interesting facts. Among the patients having serum iPTH level between $15-65 \mathrm{pg} / \mathrm{ml}$, 19 developed no symptoms of hypocalcaemia (45.2\%), 15 developed transient hypocalcaemia (35.7\%) \& none developed permanent hypocalcaemia. But the other patients showing serum iPTH level $<15 \mathrm{pg} / \mathrm{ml}$, included the 3 cases (7.2\%) with permanent hypocalcaemia, 4 cases $(9.5 \%)$ developing transient hypocalcaemia \& 1 case $(2.4 \%)$ without any symptoms of hypocalcaemia.

\section{DISCUSSION}

Thyroid diseases are growing in incidence with increasing number of total thyroidectomies are being performed as a definitive treatment for WDTC as well as bilateral benign diseases like MNG \& $A G$, as a result of which incidence of hypocalcaemia \& hypoparathyroidism, being one of the commonest complication of thyroid surgeries, are also on the rise. ${ }^{17,18}$ The hypocalcaemia developing in post thyroidectomy patients can be temporary, resolving within a few weeks to few months, or permanent, lasting for longer than 1 year, sometimes requiring lifelong oral calcium and vitamin D supplementation. ${ }^{7}$ Temporary hypocalcaemia can be subclassified into Biochemical hypocalcaemia(BH) or Symptomatic hypocalcaemia(SH), which usually develops 2448 hours after total thyroidectomy. ${ }^{2}$ So during this period patients need close monitoring both biochemically as well as clinically for development of signs \& symptoms of hypocalcaemia.

On review of literature various factors have been found to be correlated to development of post-thyroidectomy hypocalcaemia. Post-operative serum calcium level has been implicated as one of the factors predicting symptomatic hypocalcaemia. ${ }^{19-21}$ According to Pfleiderer et al, serum calcium level $<7.6 \mathrm{mg} \%$ on day 1 post-operatively has $95 \%$ specificity in predicting SH. ${ }^{22}$ In the present study we measured serum calcium level 6 hours \& 12 hours postoperatively. It has been found that patients on positive slope have lesser chances of occurrence of symptomatic hypocalcaemia \& permanent hypocalcaemia than those on non-positive slope. Similar results have also been reported by Nahas ZS et al, who concluded patients on positive slope can be safely discharged 24 hours post-operatively with patient education with or without calcium supplementation. He also reported that patients on non-positive slope with serum calcium level $>$ or $=8 \mathrm{mg} / \mathrm{dl}$ at 12 hours post-operatively are less likely to develop significant hypocalcaemia after 24 hours post-operatively. ${ }^{23}$ Lombardi et al suggested single serum calcium measurement 12 hours post-operatively after total thyroidectomy. ${ }^{24}$ In the present study we used cut off of $7.5 \mathrm{mg} \%$ as a predictive factor for development of Hypocalcaemia, which has a sensitivity of $73 \%$ \& specificity of $84 \%$, as recorded by Pradeep PV et al. ${ }^{25}$ Lo CY et al used serum calcium level of $7.2 \mathrm{mg} \%$ as cut off for defining hypocalcaemia. ${ }^{26}$

Another factor closely related to development of post thyroidectomy hypocalcaemia is serum iPTH, which has been reportedly measured in various studies across literature search, both intra- \& post-operatively. 2, 26-29 Noordzij et al analysed 9 observational studies \& reported that iPTH level recorded 6 hours post-operatively had sensitivity of $96.4 \%$ \& specificity of $91.4 \%$ in detecting post-operative hypocalcaemia. ${ }^{2}$ Slightly different observation was made by Payne et al, who had serial measurement of iPTH levels 6,12 \& 20 hours post-operatively, with 12 hour value came out to be the most sensitive in prediction of hypocalcaemia.28 In another report by Lombardi et al, multiple measurements of iPTH at 2,4,6,24 \& 48 hours post-operative were recorded with the observation that 4 hour \& 6 hourly levels had best predictive values for development of hypocalcaemia. ${ }^{24}$ Thus there has been no definite guideline indicating the best time of collection of sample for serum iPTH post operatively although this is considered to be positively correlated to development of hypocalcaemia \& so in the present study we measured iPTH levels 6 hours post operatively. In the absence of consensus data regarding cut off values of iPTH predicting hypocalcaemia, we found that patients having serum iPTH level between 15-65 $\mathrm{pg} / \mathrm{ml}$ showed lesser propensity to develop hypocalcaemia in comparison to those with serum iPTH level $<15 \mathrm{pg} / \mathrm{ml}$. In the study reported by Noordzij et al, mean PTH was $13.52 \mathrm{pg} / \mathrm{ml}$ in patients who developed hypocalcaemia, closely resembling our findings. ${ }^{2}$ In the same study, literature review revealed that intraoperative PTH monitoring was less sensitive \& specific than post-operative values in predicting hypocalcaemia, ${ }^{2}$ thus rationalizing our choice of measurement of iPTH post operatively.

Patients of Indian subcontinent have been reported to have low serum Vitamin D levels as reported in various studies. ${ }^{30,31}$ Serum Vitamin D levels have been considered as a predictive factor in post thyroidectomy hypocalcaemia as it plays a central role in calcium kinetics, especially in postoperative period. ${ }^{22,33}$ It has been reported that low vitamin D levels are associated with 28 times increased chance of development of post total thyroidectomy clinically significant hypocalcaemia. ${ }^{34}$ In our study it has been found that all the 3 cases who developed permanent hypocalcaemia were suffering from vitamin D deficiency whereas patients with normal vitamin D levels posed lesser risk of developing significant hypocalcaemia. In a recent study, it has been pointed out by Danan and Shonka that vitamin D level is a significant predictor of postoperative hypocalcaemia, even in patients in whom $\geq 3$ parathyroid glands were identified. 35

Some reports have suggested preoperative calcium levels to predict postoperative hypocalcaemia. ${ }^{34}$ Yamashita et al, noted that patients developing hypocalcaemia had lower preoperative calcium levels. ${ }^{33}$ But in our present study we excluded patients with hypocalcaemia or any disorder of calcium metabolism.

The number of parathyroid glands preserved during surgery has an inverse relationship to the chances of development of post-operative hypocalcaemia. There are various opinions regarding the minimum number of parathyroid glands to be preserved in order to prevent postoperative hypocalcaemia as some reports suggested that at least 3 parathyroids are to be saved whereas others are of the opinion that at least 2 functional glands will be sufficient in preventing postoperative hypocalcaemia.1,36,37 In our observation patients with only two parathyroid glands identified per-operatively has more chances of developing hypocalcaemia \& those in whom all four parathyroid glands were preserved, very low risk of hypocalcaemia is associated. 
Furthermore, preservation of functional parathyroid gland with intact blood supply is found to be of immense importance than mere identification of the glands. Permanent devascularisation \& resultant hypoparathyroidism can be prevented by clear anatomical knowledge \& resorting to meticulous dissection near the parathyroid gland and inferior thyroid artery. Main branch of the inferior thyroid artery along with its branches to parathyroid gland needs to be identified prior to application of any ligature near the parathyroid glands. Use of bipolar cautery forceps close to the thyroid gland leaves the parathyroid glands laterally with its blood supply unjeopardized. This technique was followed in all the cases in our series. It has also been noted in studies that searching for parathyroid glands increases the risk of injury, further causing hypocalcaemia.38,39 Literature review shows that development of hypocalcaemia post-operatively depends on experience of the surgeon \& operative technique used. ${ }^{40,41}$ In the present study this factors were neutralised as all the patients were operated by the same group of surgeons well trained \& experienced in thyroid surgery with uniformity in the surgical technique.

In our series it has been noted that with increase in the size of thyroid nodule, chances of hypocalcaemia increases, which may be attributed to increasing anatomical distortion \& difficulty in parathyroid gland localization, leading to increase in the chances of devascularisation of the parathyroid glands. Another factor which have been found to correlate with the development of post-operative hypocalcaemia in the present study is the nature of primary surgery. Patients undergoing completion thyroidectomy for histopathological report of WDTC in a previously benign (based on pre-operative FNAC) thyroid nodule entails increased chances of development of post-operative hypocalcaemia. Factors contributing to this may be more chances of fibrosis \& compromised vascularity to parathyroid glands in a previously operated neck as well as unknown functional status of the parathyroid glands on the previously operated side. But this is in contrary to the findings of González-Botas and Piedrahita ${ }^{42}$ and Merchavy et al, ${ }^{43}$ who reported that postoperative hypocalcaemia was less common in patients with completion thyroidectomy than in patients who underwent total thyroidectomy. However, other authors like Godlewska $P$, et al reported incidence of hypoparathyroidism to be $15.74 \%$ following radical thyroid surgery versus $23.43 \%$ after completion thyroidectomy, supporting the data obtained in the current study. 44 Other factors like release of calcitonin into the circulation while manipulating the thyroid gland per-operatively and postoperative dilutional hypocalcaemia have also been implicated by some authors in development of hypocalcaemia, although these were beyond the scope of the present study.

\section{CONCLUSIONS}

In the present study, we have found that development of hypocalcaemia post thyroidectomy is multifactorial, some of which are predictable \& some of which are correctable in order to reduce the chances of development of hypocalcaemia. Although we considered pre-operative assessment of serum calcium, vitamin D \& iPTH, which are not normally ordered prior to routine thyroid surgery but these are important predictors of development of hypocalcaemia post-operatively, thus helping in identifying at risk patients. Furthermore, these are correctable factors preoperatively which reduce the risk of developing hypocalcaemia post-operatively. In the post-operative period also we monitored serum calcium level by serial monitoring \& early post-operative iPTH monitoring, which although apparently incurs additional costs to the patients but overall it helps in early identification of patients who are prone to develop significant hypocalcaemia in combination with the per-operative factors \& ultimately helps in early institution of definitive replacement therapy, preventing unnecessary emergency readmission \& helps in reducing the duration of hospital stay by facilitating early discharge. Thus, overall assessment of these parameters will result in reduced burden on the healthcare system in a developing country like India.

\section{REFERENCES}

[1] Pattou F, Combemale F, Fabre S, et al. Hypocalcaemia following thyroid surgery: incidence and prediction of outcome. World J Surg 1998;22(7):718-24.

[2] Noordzij JP, Lee SL, Bernet VJ, et al. Early prediction of hypocalcaemia after thyroidectomy using parathyroid hormone: an analysis of pooled individual patient data from nine observational studies. J Am Coll Surg 2007;205(6):748-54.

[3] Asari R, Passler C, Kaczirek K, et al. Hypoparathyroidism after total thyroidectomy: a prospective study. Arch Surg 2008;143(2):132-8.

[4] Pisanu A, Saba A, Coghe F, et al. Early prediction of hypocalcaemia following total thyroidectomy using combined intact parathyroid hormone and serum calcium measurement. Langenbecks Arch Surg 2013;398(3):423-30.

[5] Shaha AR, Jaffe BM. Parathyroid preservation during thyroid surgery. Am J Otolaryngol 1998;19(2):113-7.

[6] Wilhelm SM, McHenry CR. Total thyroidectomy is superior to subtotal thyroidectomy for management of Graves' disease in the United States. World J Surg 2010;34(6):1261-4.

[7] Puzziello A, Rosato L, Innaro N, et al. Hypocalcaemia following thyroid surgery: incidence and risk factors. A longitudinal multicenter study comprising 2,631 patients. Endocrine 2014;47(2):537-42.

[8] Reeve T, Thompson NW. Complications of thyroid surgery: how to avoid them, how to manage them and observations on their possible effect on the whole patient. World J Surg 2000;24(8):971-5.

[9] La Quaglia MP, Black T, Holcomb GW 3rd, et al. Differentiated thyroid cancer: clinical characteristics, treatment and outcome in patients under 21 years of age who present with distant metastases. A report from the surgical discipline committee of the children's cancer group. J Pediatr Surg 2000;35(6):955-60.

[10] Mowschenson PM, Hodin RA. Outpatient thyroid and parathyroid surgery: a prospective study of feasibility, safety and costs. Surgery 1995;118(6):1051-4.

[11] Bhattacharyya N, Fried MP. Assessment of the morbidity and complications of total thyroidectomy. Arch Otolaryngol Head Neck Surg 2002;128(4):38992. 
[12] McHenry CR. "Same-day" thyroid surgery: an analysis of safety, cost savings and outcome. Am Surg 1997;63(7):586-90.

[13] Schwartz AE, Clark OH, Ituarte P, et al. Therapeutic controversy: Thyroid surgery - the choice. J Clin Endocrinol Metab 1998;83(4):1097-105.

[14] Youngwirth L, Benavidez J, Sippel R, et al. Postoperative parathyroid hormone testing decreases symptomatic hypocalcaemia and associated emergency room visits after total thyroidectomy. Surgery 2010;148(4):841-4.

[15] Garrahy A, Murphy MS, Sheahan P. Impact of postoperative magnesium levels on early hypocalcaemia and permanent hypoparathyroidism after thyroidectomy. Head Neck 2016;38(4):613-9.

[16] Gross ND. Postoperative hypocalcaemia-the difference a definition makes. Commentary. Head Neck 2010;32(3):283-4.

[17] Magreni A, Bann DV, Schubart JR, et al. The effects of race and ethnicity on thyroid cancer incidence. JAMA Otolaryngol Head Neck Surg 2015;141(4):319-23.

[18] Puzziello A, Gervasi R, Orlando G, et al. Hypocalcaemia after total thyroidectomy: could intact parathyroid hormone be a predictive factor for transient postoperative hypocalcaemia? Surgery 2015;157(2):344-8.

[19] Husein M, Hier MP, AI-Abdulhadi K, et al. Predicting calcium status post thyroidectomy with early calcium levels. Otolaryngol Head Neck Surg 2002;127(4):28993.

[20] Adams J, Andersen P, Everts E, et al. Early postoperative calcium levels as predictors of hypocalcaemia. Laryngoscope 1998;108(12):1829-31.

[21] Moore C, Lampe H, Agarwal S. Predictability of hypocalcaemia using early post-operative serum calcium levels. J Otolaryngol 2001;30(5):266-70.

[22] Pfleiderer AG, Ahamd N, Draper MR, et al. The timing of calcium measurements in helping to predict temporary and permanent hypocalcaemia in patients having completion and total thyroidectomies. Ann R Coll Surg Engl 2009;91(2):140-6.

[23] Nahas ZS, Farrag TY, Lin FR, et al. A safe and cost effective short hospital stay protocol to identify patients at low risk for the development of significant hypocalcaemia after total thyroidectomy. Laryngoscope 2006;116(6):906-10.

[24] Lombardi CP, Raffaelli M, Prince P, et al. Early prediction of post thyroidectomy hypocalcaemia by a single iPTH measurement. Surgery 2004;136(6):123641.

[25] Pradeep PV, Ramalingam K, Jayashree B. Post total thyroidectomy hypocalcaemia: a novel multi-factorial scoring system to enable its prediction to facilitate an early discharge. J Postgrad Med 2013;59(1):4-8.

[26] Lo CY, Luk JM, Tam SC. Applicability of intra-operative parathyroid hormone assay during thyroidectomy. Ann Surg 2002;236(5):564-9.

[27] Warren FM, Andersen PE, Wax MK, et al. Intraoperative parathyroid hormone levels in thyroid and parathyroid surgery. Laryngoscope 2002;112(10):1866-70.
[28] Payne RJ, Hier MP, Tamilia M, et al. Post-operative parathyroid hormone level as a predictor of post thyroidectomy hypocalcaemia. J Otolaryngol 2003;32(6):362-7.

[29] Soon PS, Magarey CJ, Campbell P, et al. Serum intact PTH as a predictor of hypocalcaemia after total thyroidectomy. ANZ J Surg 2005;75(11):977-80.

[30] Babu US, Calvo MS. Modern India and Vitamin D dilemma: evidence for the need of a national food fortification program. Mol Nutr Food Res 2010;54(8):1134-47.

[31] Khadgawat R, Brar KS, Gahlo M, et al. High prevalence of Vitamin D deficiency in Asian Indian patients with fragility hip fracture: a pilot study. J Assoc Physicians India 2010;58:539-42.

[32] Erbil Y, Bozbors A, Ozbey N, et al. Predictive value of age \& serum parathormone and vitamin D3 levels for post-operative hypocalcaemia after total thyroidectomyfor non-toxic multinodular goitre. Arch Surg 2007;142(12):1182-7.

[33] Yamashita H, Noguchi S, Murakami T, et al. Predictive risk factors for post-operative tetany in female patients with Graves' disease. J Am Coll Surg 2001;192(4):465-8.

[34] Erbil Y, Barbaros U, Temel B, et al. The impact of age, Vitamin D (3) level, and incidental parathyroidectomy on postoperative hypocalcaemia after total or near total thyroidectomy. Am J Surg 2009;197(4):439-46.

[35] Danan D, Shonka DC Jr. Preoperative vitamin D level as predictor of post-thyroidectomy hypocalcaemia in patients sustaining transient parathyroid injury. Head Neck 2017;39(7):1378-81.

[36] Olson JA Jr, DeBenedetti MK, Baumann DS, et al. Parathyroid autotransplantation during thyroidectomy. Results of long-term follow-up. Ann Surg 1996;223(5):472-80.

[37] Thomusch O, Machens A, Sekulla C, et al. The impact of surgical technique on postoperative hypoparathyroidism in bilateral thyroid surgery: a multivariate analysis of 5846 consecutive patients. Surgery 2003;133(2):180-5.

[38] Page C, Strunski V. Parathyroid risk in total thyroidectomy for bilateral, benign, multinodular goitre: report of 351 surgical cases. J Laryngol Otol 2007;121(3):237-41.

[39] Rosato L, Avenia N, Bernante P, et al. Complications of thyroid surgery: analysis of a multicentric study on 14,934 patients operated on in Italy over 5 years. World J Surg 2004;28(3):271-6.

[40] Kotan C, Kosem M, Alquan E, et al. Influence of the refinements of surgical technique and surgeons experience on the rate of complications after total thyroidectomy for benign thyroid diseases. Acta Chir Belg 2003;103(3):278-81.

[41] Sosa JA, Bowman HM, Tielsch JM, et al. The importance of surgeon experience for clinical and economic outcomes from thyroidectomy. Ann Surg 1998;228(3):320-30.

[42] González-Botas JH, Piedrahita DL. Hypocalcaemia after total thyroidectomy: incidence, control and treatment. Acta Otorrinolaringol Esp 2013;64(2):102-7. 
[43] Merchavy S, Marom T, Forest VI, et al. Comparison of the incidence of postoperative hypocalcaemia following total thyroidectomy vs completion thyroidectomy. Otolaryngol Head Neck Surg 2015;152(1):53-6.
[44] Godlewska P, Kaniewski M, Stachlewska-Nasfeter E, et al. Parathyroid hypofunction after total thyroidectomy for differentiated thyroid carcinoma -- perspectives after long term observation \& treatment. Wiad Lek 2001;54(Suppl 1):398-404. 